\title{
Support for Dialysis Therapy in Vietnam, Cambodia, and Myanmar by Japanese Societies in the Field of Blood Purification
}

\author{
Kenichi Kokubo ${ }^{\text {a-e }}$ Kozue Kobayashia, e Sunichiro Urabe ${ }^{a-c, e, f}$ \\ Hirokazu Matsubarab,c, e,g Tomotaka Naramurab-e, h Haruki Wakai ${ }^{\text {b, c, i }}$ \\ Toshihide Naganuma ${ }^{b-d, j} \quad$ Fumitaka Nakajima ${ }^{b, c, k}$ Nobuhisa Shibahara ${ }^{b-d, ~}$ I \\ Toru Hyodo ${ }^{b-d, f}$ Kenichi Matsudab, $m$ Kazunari Yoshidab, c, n \\ Akihiro C. Yamashitab-d, o Hideki Kawanishi ${ }^{b-d, p}$

\begin{abstract}
${ }^{a}$ Kitasato University School of Allied Health Sciences, and ${ }^{b}$ NGO Ubiquitous Blood Purification International, Kanagawa, 'Assistance Council for Establishing a Dialysis Specialists' System in Cambodia, dHuman Resource Development Program Committee for Dialysis Specialists in Developing Countries, Japanese Society for Dialysis Therapy, and ${ }^{\mathrm{e} C o m m i t t e e ~ o n ~ I n t e r n a t i o n a l ~ A f f a i r s, ~ J a p a n e s e ~ S o c i e t y ~ f o r ~ T e c h n o l o g y ~ o f ~ B l o o d ~ P u r i f i c a t i o n, ~}$ Tokyo, ${ }^{f}$ Eijin Clinic, Kanagawa, ${ }^{9}$ Tanaka Urology Clinic, Nara, ${ }^{\text {h}}$ Faculty of Medical Science, University of East Asia, Yamaguchi, 'Shinagawa Garden Clinic, Tokyo, ${ }^{j}$ Graduate School of Medicine, Osaka City University, ${ }^{k}$ Moriguchi Keijinkai Hospital, and 'Arisawa General Hospital, Osaka, 'm School of Medicine, Yamanashi University, Yamanashi, ${ }^{n}$ Kitasato University School of Medicine, Kanagawa, ${ }^{\circ}$ Department of Chemical Science and Technology, Hosei
\end{abstract} \\ University, Tokyo, and ${ }^{\mathrm{P} T}$ suchiya General Hospital, Hiroshima, Japan
}

\section{Keywords}

Dialysis · Japan · Vietnam · Cambodia · Myanmar · Blood purification · Support activities - Educational activities

\begin{abstract}
With recent economic development in Southeast Asia, there have been improvements in medical services and healthcare provision. This has led to increased numbers of dialysis patients and increased numbers of dialysis facilities in the region. To assist economically developing countries in managing this change, support projects from Japan have been conducted in the region since around 2007. This article summarizes and discusses Japan's support activities, in which some of the authors were directly involved, in Vietnam, Cambodia, and Myanmar. Initial support was mainly organized by the non-governmental organization Ubiquitous Blood
\end{abstract}

\section{KARGER}

(C) 2017 S. Karger AG, Basel
Purification International (NGO UBPI), and currently several organizations in the field of blood purification work together to offer ongoing support in the region. Many positive changes have resulted from these activities in Southeast Asia, but challenges remaining for the future are to establish an educational system for each dialysis specialty and develop dialysis techniques ensuring high treatment quality and safety.

(c) 2017 S. Karger AG, Basel

\section{Introduction}

Recently, economic development in Southeast Asia has advanced remarkably with attendant improvements in medical services and healthcare provision. These improvements have, in turn, increased the numbers of di- 
Table 1. Japanese societies in the field of blood purification that are currently involved in support activities in economically developing countries in Southeast Asia

NGO Ubiquitous Blood Purification International (UBPI)

President: Hideki Kawanishi

Secretary General: Toru Hyodo

Japanese Assistance Council for Establishing Dialysis Specialists'

System in Cambodia (JAC-DSC)

Chairman: Hideki Kawanishi

Vice Chairpersons: Toru Hyodo, Kenichi Kokubo

Secretary General: Haruki Wakai

Human Resource Development Program Committee for Dialysis

Specialists in Developing Countries, Japanese Society for Dialysis

Therapy (JSDT)

Chairman: Akihiro C. Yamashita

Vice Chairman: Toru Hyodo

Committee on International Affairs, Japanese Society for

Technology of Blood Purification (JSTB)

Chairman: Kenichi Kokubo

Vice Chairpersons: Teruhiko Miyamoto, Hiroko Yamamoto

alysis patients and dialysis facilities in the region. To assist economically developing countries to manage this change, support projects from Japan were started in Vietnam and Cambodia around 2007, mainly organized by the nongovernmental organization Ubiquitous Blood Purification International (NGO UBPI). Currently, several organizations in the field of blood purification carry out support activities in the region (Table 1), and these organizations work together seamlessly. This article summarizes and discusses the history of Japan's support activities, including those of some of the authors, in Vietnam, Cambodia, and Myanmar.

\section{Initial Activity (up to around 2014)}

Vietnam received support initially through academic exchanges with nephrologists at Bach Mai Hospital in Hanoi. Thereafter, support activities expanded to include establishing a dialysis room through donations of dialysis machines in the period 2004-2011, coordinated by Dr. Nobuhisa Shibahara.

Support activities expanded to the launch of a blood purification center at Sen Sok International University Hospital, Cambodia in 2010. The Cambodia-Japan Friendship Blood Purification Center was officially inaugurated on March 9, 2010 through the efforts of the late Dr. Hideo Hidai, Former Executive Director of NGO
UBPI. Patients previously treated in Vietnam first received hemodialysis treatment at the center in March 2010. Dr. Shibahara coordinated support from Takatsuki Rotary Club of Japan to establish Siem Reap Referral Hospital Dialysis Center, through the donation of dialysis machines and systems in 2014.

In 2011, investigations into dialysate purification were started in Vietnam and Cambodia as a special project of the 17th Annual Congress of the Japanese Society for Hemodiafiltration (Congress President, Dr. Toru Hyodo). Myanmar also benefited from a similar project, which was carried out in 2013. Based on the results of these investigations, an article summarizing dialysis therapy in economically developing countries in Southeast Asia and an overview of the quality of dialysate in the three countries was published [1]. In brief, the investigation identified high endotoxin levels in the facilities, and many viable bacteria were also detected.

Initial activity to support dialysis therapy was led by NGO UBPI around 2012. Activities included newly supporting the establishment of dialysis centers, donation of dialysis machines, short-term training onsite and in Japan, and surveys of dialysate quality. Through these activities, we gradually came to understand that, even with the introduction of dialysis equipment, there was insufficient training to develop human resources for practical treatment in these countries and that human resource development and support from an academic standpoint were becoming increasingly important. Because supporting dialysis services from an academic standpoint seems to be an effective strategy in economically developing countries, we decided to start a dialysate purification project.

\section{Support Activities of NGO UBPI (2013-2015)}

The dialysate purification project commenced in Vietnam, Cambodia, and Myanmar in 2013. Clinical engineers collaborated with local engineers on the installation of endotoxin retentive filters (ETRF) to achieve pure dialysate. We evaluated the quality of dialysate at 6 months and 1 year after the project started. Endotoxin levels and viable bacterial count were both maintained below the limit of detection [2].

In December 2013, NGO UBPI accepted 4 trainees from Myanmar for short-term training in dialysis therapy and continuous renal replacement therapy (CRRT) at Kitasato University, Hashimoto Clinic, Nihon University Itabashi Hospital, and Yamanashi University, Japan. This followed an academic affiliation between the University of Medicine
56

Blood Purif 2017;44(suppl 1):55-61 DOI: $10.1159 / 000479621$
Kokubo et al. 

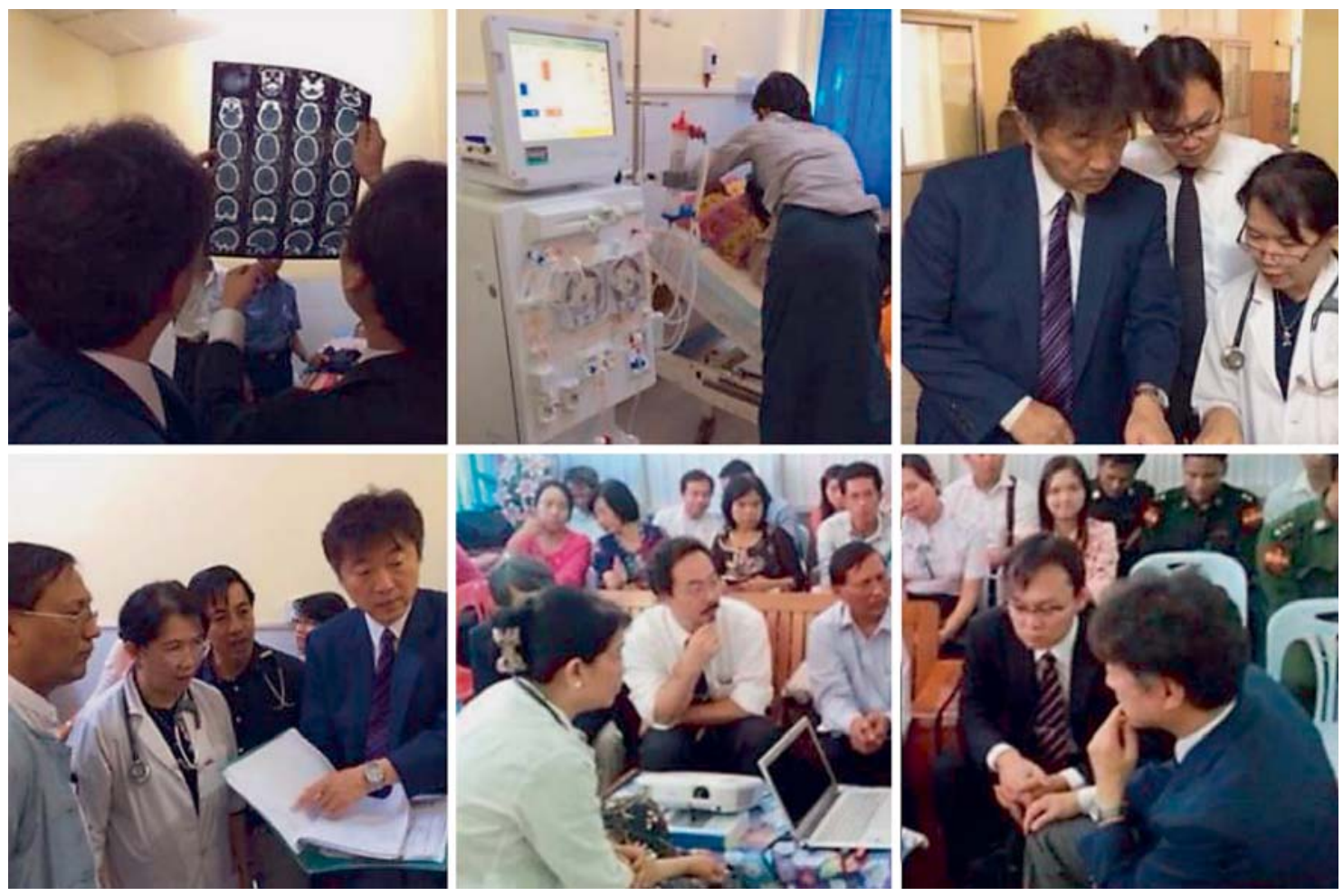

Fig. 1. The team from Myanmar and Japan that successfully managed the first and second cases of acute renal failure from venomous snake bites with online HDF therapy in Myanmar in 2014.

2, Yangon, Myanmar and Kitasato University Graduate School of Medical Sciences in October 2013. A collaborative study between the two universities was started to establish successful management of acute kidney injury (AKI) following snakebite envenomation. A physician from the University of Medicine 2, Yangon, underwent 2 months of training in the modalities of dialysis treatment and CRRT in Japan from June to July 2014. From the various discussions held, we learned about the current status and needs in Myanmar, which led to the prompt introduction of CRRT in the country. In December 2014, acute renal failure from snakebite envenomation was successfully managed by online HDF therapy in 2 cases with the support of Dr. Kenichi Matsuda (Fig. 1). The therapy was performed safely and the patients survived with full recovery of kidney function.

In Cambodia, we continued support activities by focusing on the procedure of arteriovenous fistula creation, mainly performed by Dr. Fumitaka Nakajima, and organized a seminar in July 2014. In September 2015, the first percutaneous transluminal angioplasty in Cambodia was successfully performed by Dr. Toshihide Naganuma in collaboration with doctors at Sen Sok International University Hospital (Fig. 2).

Support for Dialysis Therapy in Vietnam, Cambodia, and Myanmar
To continue support dialysis treatment and care from an academic standpoint in the economically developing countries, a dialysate purification project was set up and ETRF installed. Pure dialysate was successfully achieved. Other activities included short-term training and lectures. Together, these activities further clarified the current status and needs of each country. The success of the first 2 cases of online HDF in Myanmar for AKI from snakebite envenomation and the first percutaneous transluminal angioplasty in Cambodia for a case of vascular access stenosis can be attributed to these support endeavors.

For enhancing human resource development and support from an academic standpoint, goals were to (1) develop human resources, including training of clinical engineers and dieticians, and establish an educational system to support the creation of educational programs and train local teachers; (2) expand the support framework through the participation of Japanese organizations in the field of blood purification; and (3) provide training in dialysis techniques, including daily management and periodic inspection of machines and daily patient management such as care of vascular access and as-

Blood Purif 2017;44(suppl 1):55-61 DOI: $10.1159 / 000479621$ 

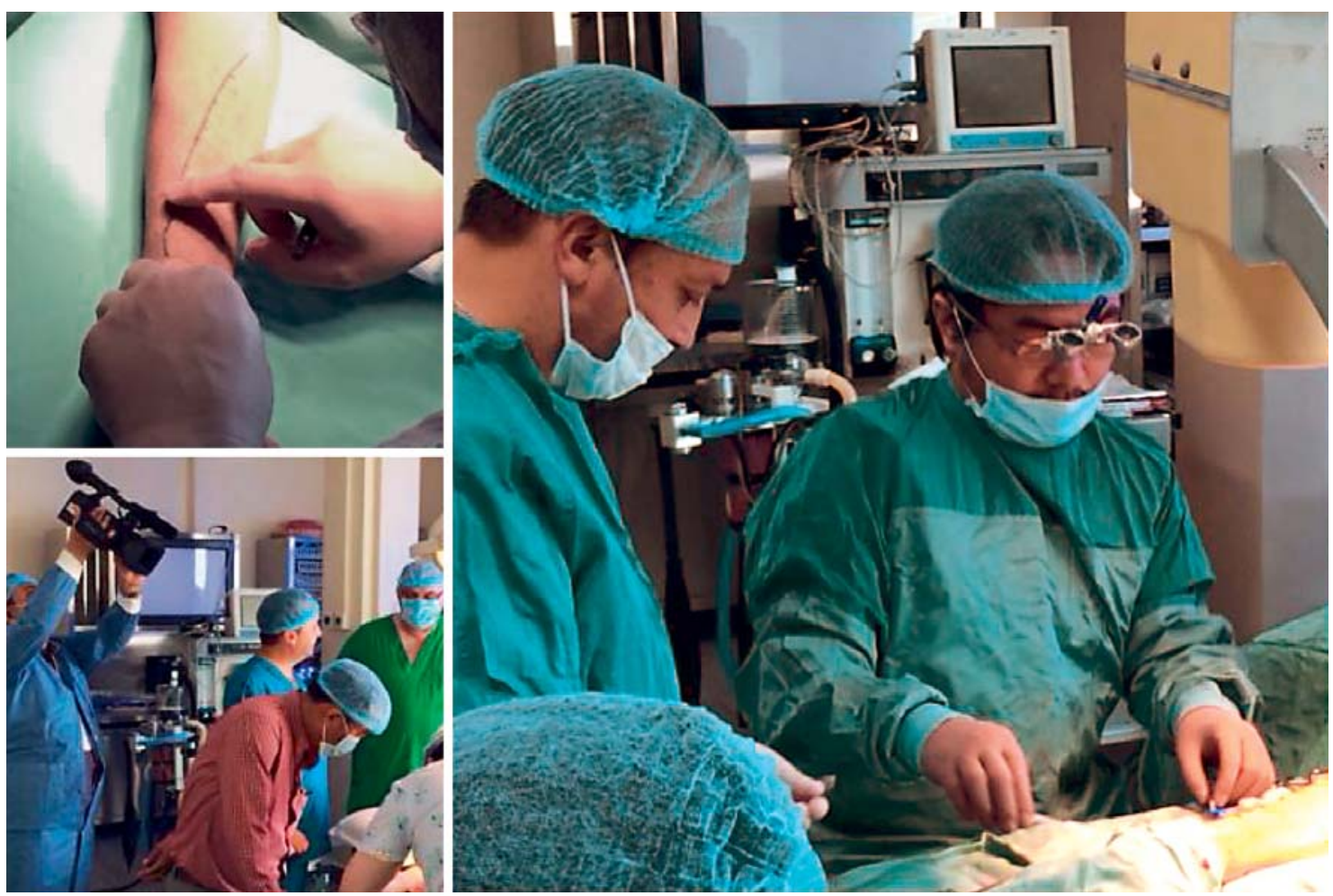

Fig. 2. First percutaneous transluminal angioplasty successfully performed in Cambodia.

sessment of dry weight. In addition, short-term training, lectures and seminars, and hands-on training could also be effective.

\section{Support Activities (2015-2017)}

We carried out support activities with the following goals:

(1) Establishment of an educational system

(2) Inauguration of an academic society in the field of blood purification

(3) Improvement of dialysis techniques and services

\section{(1) Establishment of an Educational System}

The Japanese Assistance Council for Establishing a Dialysis Specialists' System in Cambodia (JAC-DSC) was established in response to a request by the president of the International University, Cambodia. We also collaborated with the university to support training of doctors and allied medical personnel as specialists in dialysis. To create a solid foundation for human resource development in Cambodia, the ultimate goal is to develop a 6-month or 1-year training course for dialysis specialists, clinical engineers, and dieticians, consisting of lectures and clinical practice at the university. In March to April 2015, JAC-DSC conducted a 1-week intensive seminar entitled "Dialysis Renal Transplantation, Clinical Engineering, and Diet Therapy for Diabetes Mellitus and Chronic Kidney Disease" for young doctors and medical students. A total of 37 lectures (50 min each) were given, covering various aspects of medicine, clinical engineering, and nutrition. Japanese doctors, clinical engineers, and dieticians participated as volunteers and lecturers (Fig. 3).

We also visited Myanmar to discuss establishing a clinical engineering course. In December 2014 and August 2016, we visited the University of Medical Technology, Mandalay and in January 2017 we visited the University of Medical Technology, Yangon. We agreed to support a new 3- to 4-year clinical engineering course and a 1-year medical engineering technology course at the University of Medical Technology, Yangon. After several discussions between the Japan International Cooperation Agency (JICA), the Japan Association of Clinical Engineers, Drs. Shigeru Okada and Yoshihiro Kimata of Okayama University, and Mr. Yoshito Sengoku, Vice Chairman of 


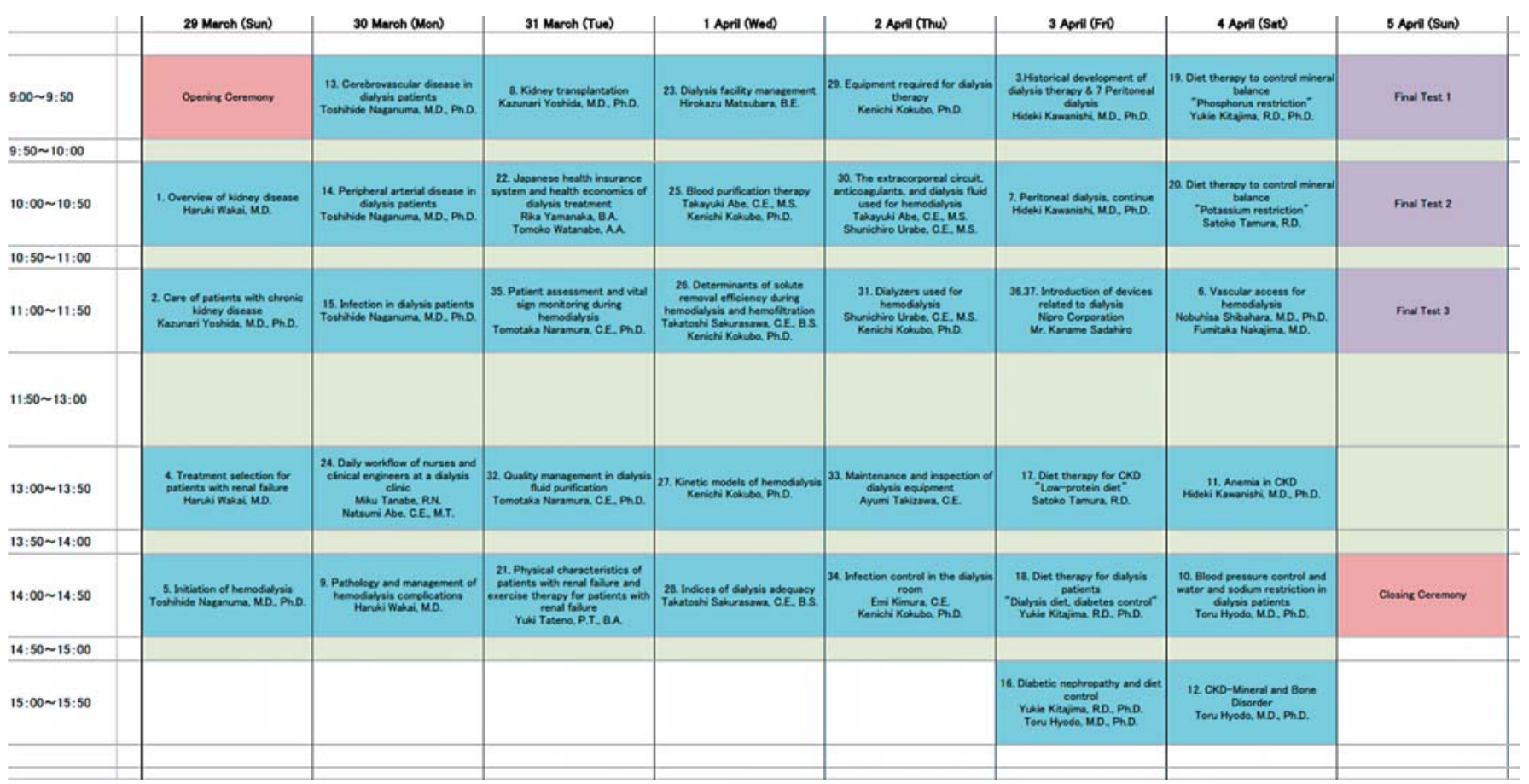

Fig. 3. Timetable of the 2015 intensive seminar held in Cambodia.

the Japan Myanmar Association, JICA decided to start a human resources development project in medical engineering. In May 2017, a team of Japanese personnel organized by JICA visited the Myanmar Ministry of Health and Sports and agreed to collaborate with them on the project. We are currently discussing the establishment of a 1-year medical engineering technologist course and a short-term dialysis specialist course at the University of Medical Technology, Yangon. Setting up such courses will, we believe, be the first step in developing an educational system for clinical engineering in Myanmar.

\section{(2) Inauguration of an Academic Society}

Academic societies in Japan seek partnerships with counterpart societies in other countries to provide support and carry out academic exchange. The Human Resource Development Program Committee for Dialysis Specialists in Developing Countries of the Japanese Society for Dialysis Therapy (JSDT) and the Committee on International Affairs of the Japanese Society for Technology of Blood Purification (JSTB) are among the bodies that can readily support such counterpart societies through training programs in Japan. The Myanmar Nephro-Urology Society has already been established, and dialysis therapy is included in its scope. Similarly,
Vietnam has several societies in the field of nephrology, although none that are related to dialysis therapy include medical personnel from diverse disciplines like JSDT does. Cambodia has no nephrology or dialysis therapyrelated academic society at present.

In December 2014, a continuing medical education course for hemodialysis treatment was held in Ho Chi Minh City. Several members of NGO UBPI participated and served as lecturers. Discussions were held with Dr. Pham Van Bui about establishing an academic society similar to JSDT as a forum for allied medical personnel, such as nurses and clinical engineers. In December 2015, the opening ceremony of the Ho Chi Minh City Society of Dialysis Therapies (HSDT) and the 1st Congress of the HSDT were successfully held in Ho Chi Minh City in collaboration with Japanese members of NGO UBPI (Fig. 4). Dr. Hyodo was appointed Honorary President of HSDT.

In Cambodia, Dr. Haruki Wakai and other members of NGO UBPI and JAC-DSC supported to the establishment of an academic society, and the 1st Congress of the Cambodian Association of Nephrology (CAN) was held in Phnom Penh in November 2016 (Fig. 5). Dr. Hyodo was appointed Honorary President of CAN. He and Dr. Hideki Kawanishi coordinated efforts for CAN 


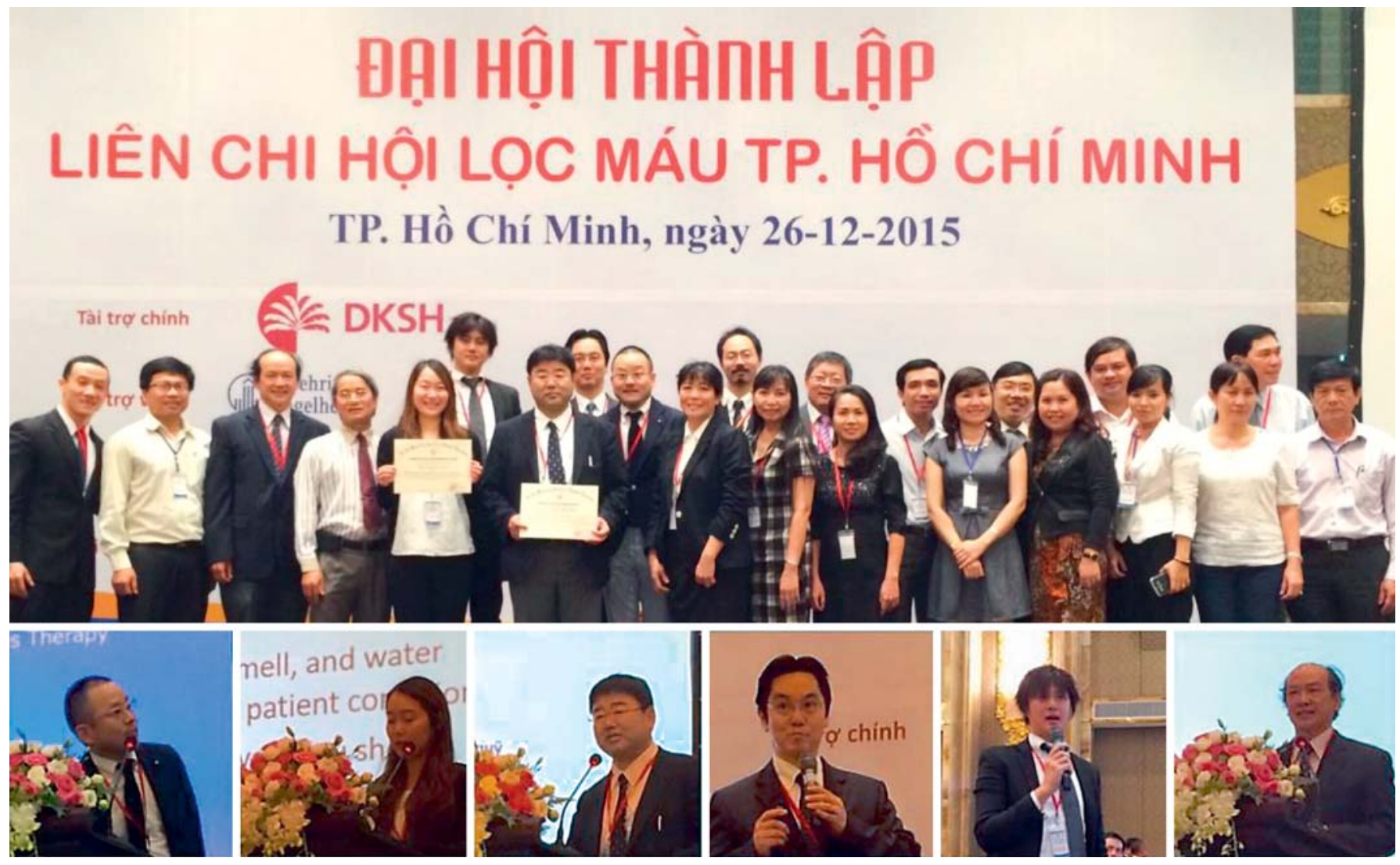

Fig. 4. The 1st Congress of the Ho Chi Minh City Society of Dialysis Therapies (HSDT).

to become an Affiliated Society of the International Society of Nephrology, which was realized on June 14, 2017.

(3) Improvement of Dialysis Techniques and Services

To improve dialysis techniques in these countries, dialysis centers modeled after Japanese centers were established in Vietnam and regular onsite seminars in Vietnam, Cambodia, and Myanmar and short-term training courses in Japan were conducted.

Specifically, Japanese-type dialysis centers were established at Nguyen Tri Phuong Hospital in Ho Chi Minh City, Vietnam to provide dialysis treatment based on that carried out in Japan. Before the dialysis center was opened, we conducted training for Vietnamese doctors and nurses. The 3-week program covered topics such as weight measurement, blood pressure measurement during treatment, cleaning dialysis rooms, function of the kidney, principles of dialysis therapy, structure of the dialyzer, blood pressure management, and weight management. The program was designed according to JSDT guidelines. We also held a seminar for dialysis patients and their families about dialysis treatment carried out in Japan. The opening ceremony for the new dialysis center was held at Nguyen Tri Phuong Hospital. In attendance were Dr. Hyodo who delivered a speech, the Consulate General of Japan in Ho Chi Minh City, and Former President of Vietnam, Mr. Truong Tan Sang, who noted in his speech that Japanese dialysis technology must be disseminated throughout Vietnam. This news was broadcast by Vietnam Television and Ho Chi Minh City Television.

Training programs in Japan were organized by JSDT in February 2017. Two doctors from Myanmar received training in Hiroshima, 2 doctors from Vietnam received training in Osaka, and 3 doctors from Cambodia received training in Tokyo and Kanagawa. One doctor from Cambodia also received training organized by JSTB in Tokyo and Kanagawa.
60
Blood Purif 2017;44(suppl 1):55-61 DOI: $10.1159 / 000479621$
Kokubo et al. 


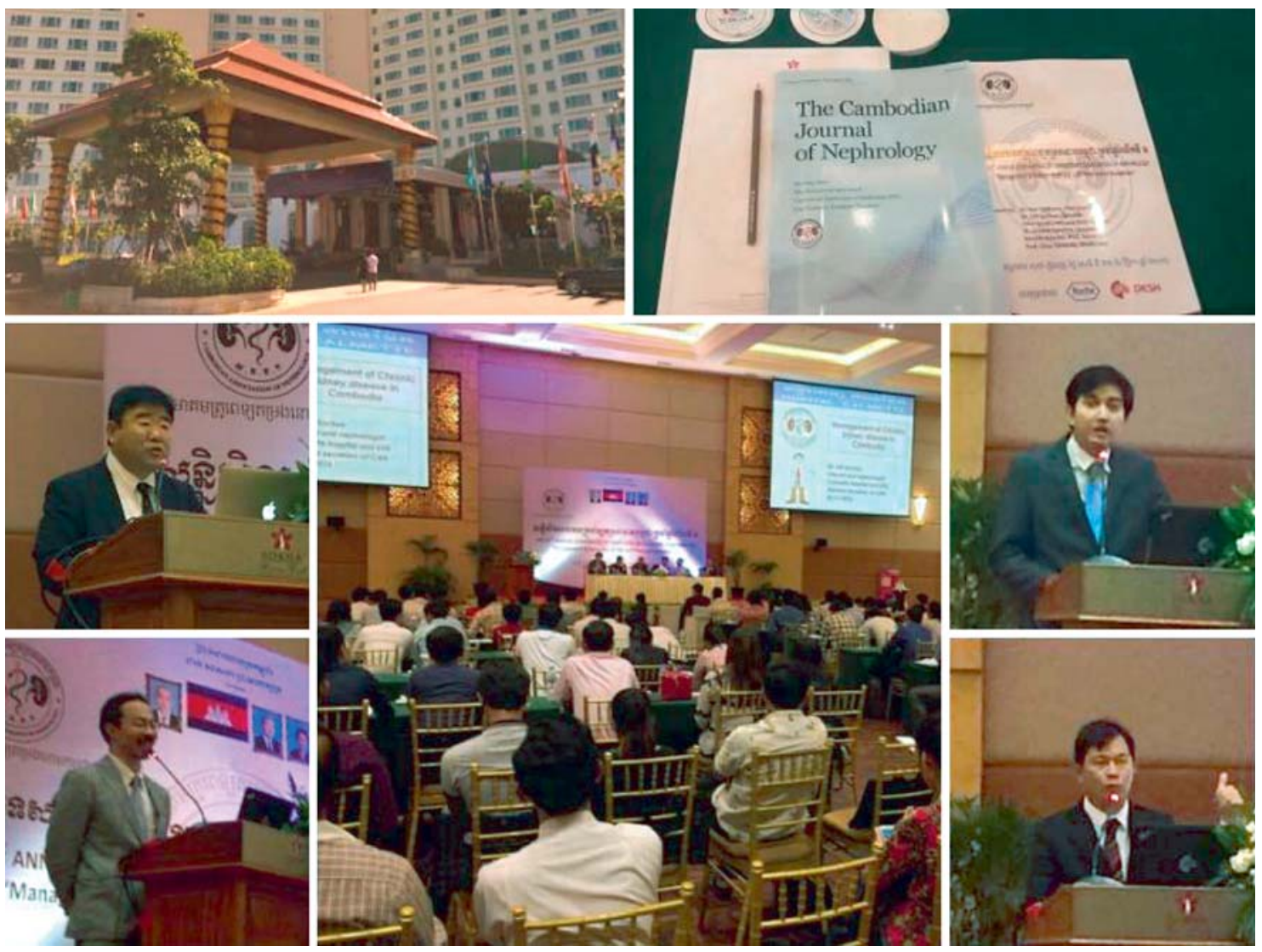

Fig. 5. The 1st Congress of the Cambodian Association of Nephrology.

In 2016, a pilot project for the maintenance of dialysis machines and evaluation of vascular access was started in Myanmar by JSTB and NGO UBPI. We visited 6 hospitals in Yangon, Nay Pyi Taw, and Mandalay for 1 week. We discussed issues such as maintaining high-quality dialysate free from ET and bacterial contamination, determining optimal operating conditions, flexibly changing operating conditions according to the patient's general condition, determining the patient's dry weight, and deciding what countermeasures should be used when there is insufficient blood flow or sudden hypotension. These issues may arise from lack of systematic and specialized study for dialysis patients. Regarding machine maintenance, the most important challenge seems to be ensuring adequate budgeting for maintenance costs. Ultimately, in many cases, maintenance costs will be lower than the cost of repair after failure if routine inspection and management can be carried out (e.g., dialysis machine cleaning, self-diagnosis, and concentration adjustment). Training of medical personnel who are familiar with dialysis equipment will also contribute to improving the quality and safety of dialysis therapy.

\section{Challenges for the Future}

In Vietnam, Cambodia, and Myanmar, as in other Southeast Asian countries, dialysis treatment is administered only by doctors and nurses. In Japan, many specialized personnel - including doctors, nurses, clinical engineers, dietitians, and physiotherapists - are involved in treatment as a team, thereby ensuring treatment quality and safety. Thus, challenges for the future in Southeast Asia are establishing an educational system for each dialysis specialty and developing dialysis techniques to ensure high treatment quality and safety.

\section{References}

1 Naramura T, Hyodo T, Kokubo K, Matsubara H, Wakai H, Nakajima F, Shibahara N, Yoshida K, Komaru Y, Kawanishi H, Kawamura A, Hidai $\mathrm{H}$, Takesawa S: Dialysis and quality of dialysate in Southeast Asian developing countries. Nephron Extra 2014;4:64-69.

2 Naramura T, Kokubo K, Kojima M, Wakai H, Hyodo T, Kawanishi H: Japan's support of hemodialysis in Southeast Asia. Contrib Nephrol 2017;189:102-109. 